\title{
REVIEW
}

\section{The face of animal cognition}

\author{
Susan D. Healy \\ School of Biology \\ University of St Andrews \\ St Andrews KY16 9TH
}

UK

Address for correspondence: Dr Susan Healy, Harold Mitchell Building, School of Biology,

Email: susan.healy@st-andrews.ac.uk

\begin{abstract}
Animal cognition is currently one of the most exciting fields within animal behaviour as an increasing number of researchers investigate the cognitive abilities of an ever-wider range of animals. Tinbergen would be proud: all four of his approaches are being pursued and we are learning much about how animals collect information and how they use that information to make decisions for their current and future states as well as what animals do not perceive or choose to ignore. Here I provide an overview of this productivity, alighting only briefly on any single example, in order to showcase the diversity of species, of approaches and the sheer mass of research effort currently underway. We are getting closer
\end{abstract}

This article has been accepted for publication and undergone full peer review but has not been through the copyediting, typesetting, pagination and proofreading process, which may lead to differences between this version and the Version of Record. Please cite this article as doi: 10.1111/1749-4877.12361. 
to understanding the minds of other animals and the evolution of cognition at an increasingly rapid rate.

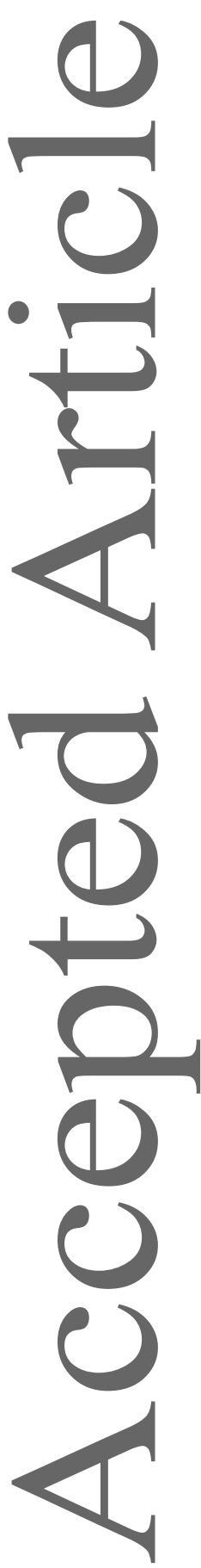


Comparative psychology used to be about pigeons, rats and monkeys. As we near the end of the second decade of the $21^{\text {st }}$ century, however, animal cognition really is becoming comparative where one is not surprised to see papers on spiders, cichlids, lizards, dogs and horses appearing alongside papers on chicks, rats and monkeys (for example see the May 2017 issue of Animal Cognition). This work is increasingly coming from a new generation of researchers building on the rich tradition of comparative psychology with its experimental rigour but with their questions now resting more broadly on all of Tinbergen's four questions, rather than on just the mechanistic basis of cognition. This means that questions such as how animal cognition has evolved, and whether cognition leads to fitness benefits, have now joined the more traditional questions of the development of cognition and what are the mechanisms that enable an animal's cognitive abilities. This new breadth to animal cognition is increasingly showing us how and why cognition plays a major role for animals in the 'real' world.

Animal cognition became a field in the 1970's and after nearly 30 years, if we take the contents of Balda, Pepperberg and Kamil's (1998) edited book (Animal Cognition in Nature) as a representative sample, things had most certainly moved on from just rats, pigeons and monkeys. Contained within that volume are various food-storing birds, a range of navigating birds, foraging insects, song learning in birds such as nightingales, white-crowned sparrows, marsh wrens and more, with Alex the parrot adding something special of his own (see review in Pepperberg, 2017). That book seemed to herald a major expansion of work on comparative cognition whereby we might begin to understand why animals vary in their cognitive abilities and what benefit cognition confers in the real world. For example, Bingman et al. (1998) described the neural mechanisms of navigation in homing-pigeon, that tremendous out-of-doors animal model that has allowed real-world distances to be put together with neural analyses, while Dyer (1998) wrote of insects using 
'snapshots' to return to rewarded locations. Species comparisons were at the heart of the work on spatial memory and its neural substrate in tits, chickadees and corvids (Balda \& Kamil, 1998; Clayton \& Lee, 1998; Shettleworth \& Hampton, 1998) and of the ontogenetic, mechanistic (proximate) and functional (ultimate) analysis of song (Baptista et al., 1998; Devoogd \& Székely, 1998; Todt \& Hultsch, 1998).

The trend of increasing diversity of species has not just continued in the first 17 years of the $21^{\text {st }}$ century, it has virtually exploded. Here I will attempt to showcase some of the key, recent developments with space only for personal preferences. In 1998, although the species diversity was increasing, the focal questions were still relatively narrow, largely on song, spatial learning and memory (in navigation in birds and insects and food storing in birds) and foraging. Now, however, researchers working on animal cognition are making progress in understanding the role that cognition plays in real-life contexts other than foraging, communication, and navigation such as sex allocation, parental care, mate choice and social interactions. So, in addition to the demonstration by psychologists that animals can do rather remarkable things such as interval timing, remembering for long periods of time, and counting numbers of items, there are increasing efforts by biologists to show why it is that animals can do these things, both by showing which animals can time/remember/count and by investigating whether those particular cognitive abilities lead to fitness benefits. Not only does this work promise serious strides forward in our understanding of the evolution of cognition, there is also the potential for a much broader impact: understanding how and why cognition varies within and among species will help us to understand how (and if) animals are equipped to deal with a rapidly changing world.

This diversity of questions and approaches might be, quite loosely, characterised into categories by Tinbergen's four questions (see also Beer, 1998; Miklosi \& Kubinyi, 2016): (1) the evolution, (2) the ontogeny, (3) the function, and (4) the mechanistic basis, of 
cognition. Most researchers use Shettleworth's definition of animal cognition, which includes all the ways that 'animals take in information through the senses, process, retain and decide to act on it' (Shettleworth, 2001).

\section{The evolution of cognition}

The evolutionary approach to animal cognition has long been typified by work on our closest cousins, the non-human primates, whereby their evolutionary proximity to us humans provides an avenue to explore how and why we behave as we do. From Köhler's chimpanzees piling up boxes to reach bananas (Köhler, 1925) and Goodall's wealth of observations of chimpanzees in the wild (1986) through to 2017, there has been a raft of work on particular kinds of primate behaviour in the laboratory, zoos and in the field. The focus has been especially directed at those behaviours in which primates appear to behave in an 'intelligent' fashion (for which, typically, read more 'human-like'), such as the piling up of boxes to reach food rather than behaviours such as mating. More recent examples include investigation of the use and function of gestures by chimpanzees Pan troglodytes (Hobaiter \& Byrne, 2014), bonobos P. paniscus (Graham et al., 2017) and other apes (e.g. olive baboons Papio anubis: Bourjade et al., 2014), which has lead to the consideration that such gesturing may have been a precursor to human language (Arbib, 2017), the nature of prosocial behaviour (Tennie et al., 2016), and the development of the field of primate linguistics (Schlenker et al., 2016).

Primates are also proving to be rather similar to humans in terms of where they look to gain information, specifically through imitating or emulating others (e.g. van de Waal et al., 2015), even if those others are only seen on video (Gunhold et al., 2014), albeit without the overimitation often seen in children (Whiten et al., 2016a). In chimpanzees, at least, such social transmission of information appears to lead to culture, which becomes more 
complex over time (Vale et al., 2017).

When seen in the non-human primates, similarities in cognitive abilities to those of humans are not unexpected. When human-like capacities are also identified in other animals, they then often leapfrog others in our estimates of their cognitive abilities. Corvids have done this for a long time but much more so since the report of tool making by New Caledonian crows Corvus moneduloides (Hunt, 1996). For example, careful observation and experimentation have shown us that ravens (C. corax) will guard food they have hidden when a peephole in a wall of the enclosure in which they have hidden food is open (and thus may have a conspecific watching them as they hide their food: Bugnyar et al., 2016). Such perspective taking is considered to require a theory of mind and was once considered a feat of which only humans (and then other primates) was capable. Crows and ravens also appear to dislike inequity (Wascher \& Bugnyar, 2013), while ravens and western scrub jays Aphelocoma californica can differentiate between knowledgeable and ignorant conspecifics when those conspecifics do or do not know where food has been hidden (Bugnyar \& Heinrich, 2005; Clayton et al., 2007). Clark's nutcrackers Nucifraga columbiana exhibit some form of self-recognition using a mirror (Clary \& Kelly, 2016), and it is now plausible to suggest corvids as a useful model for human cognitive neuroscience (Clayton \& Emery, 2015).

But corvids are just the tip of the iceberg. Dogs are also emerging as a new model, not least because they are remarkably good at following human gaze (e.g. Lakatos et al., 2012; Teglas et al., 2012), and at following pointing (Lakatos et al., 2012; Teglas et al., 2012), plus they provide an ease of access to multiple dogs (via pet owners) without requiring the costs of laboratory housing (although this comes at the cost of uncontrolled rearing conditions and variation in experience). Parrots, too, were once represented by Alex, the talking African Grey Parrot Psittacus erithacus, but there is an increasing 
diversity of species, including kea Nestor notabilis (e.g. Gajdon et al., 2013), macaws (Schuck-Paim et al., 2009), and cockatoos (e.g. Auersperg et al., 2014), with now more than 60 other species studied to some extent (Cussen, 2017). With the addition of fish (Petrazzini et al., 2016), reptiles (Kis et al., 2015; Petrazzini et al., 2017), an increasing diversity of mammals such as goats (Nawroth et al., 2016), horses (Smith et al., 2016), and spotted hyaenas Crocuta crocuta (Holekamp \& Benson-Amram, 2017), it is clear that impressive cognitive abilities are widespread, raising the question as to the extent to which these abilities share common, ancestral mechanisms, or whether convergence is much more widespread than is typically assumed.

\section{The ontogeny of cognitive abilities}

Although song learning in birds is not always included in textbooks of animal cognition, it is an iconic system in which the ontogenetic acquisition of information has been rigorously explored. And yet, after decades of work, there is still much to be learned. One aspect that is receiving considerable attention is the role that early-life conditions play on song learning: it is now clear that song learning is hugely affected by food restriction, brood size manipulation or variation in circulating corticosterone levels (a stress hormone; Suzuki et al., 2014), leading to males singing shorter songs that contain fewer syllables (Schmidt et al., 2014; Spencer et al., 2003), and to impairment in auditory learning in females (Farrell et al., 2016). Although adult female zebra finches Taeniopygia guttata also prefer the songs of control males rather than those of males who were stressed in early life (Spencer et al., 2005) female choices seem to depend on her own developmental circumstances and, as a result, does not always seem to be for a 'good' male. For example, female song sparrows Melospiza melodia that have suffered food restriction when young were less selective when offered a choice between conspecific and heterospecific songs (Schmidt et 
al., 2013) while female zebra finches from large broods (where it is assumed that there is more stress than in a small brood) prefer songs of males that are also from large broods (Holveck \& Riebel, 2010).

Because these manipulations appear to vary in their effect and impact, they are proving to be useful in investigating the mechanistic basis of cognitive development. For instance, food restriction or corticosterone manipulations in young song sparrows lead to males singing simpler songs but only the food-restricted males copied their tutors less accurately. This difference copying accuracy shows that although both food restriction and increased corticosterone were stress manipulations, the lack of nutrients must play a different role in the developing brain of the young song sparrow than does corticosterone.

Developmental stress also appears to impact other cognitive capacities: young foodrestricted Western scrub jays were poorer at spatial learning and memory as adults than were control birds (Pravosudov et al., 2005), although the birds did not differ in their performance on an associative learning task that required colour cues rather than spatial cues. Evidence of more general effects of early-life food restriction on the associative learning capabilities of another scrub jay, the Florida scrub-jay, Aphelocoma coerulescens (Bebus et al., 2016), might suggest, however, that like the variation in impact on cognitive abilities caused by differing early-life stressors on male songbirds, cognition is not a singular trait to be modified wholesale. One feature that might also play a role in explaining this variation is the relevance of the particular stressor to the species under study, as seen specifically in the negative impact of social isolation on cognition in young dairy calves (Costa et al., 2016).

Impairments of the kind described in young kittiwakes Rissa tridactyla when stressed (using increased levels of corticosterone), suggests that it may not be just cognition that is affected by stress during early life. These birds took longer to learn how to do a 
task (either opening a dish to obtain food or learning the way to escape from an enclosure; Kitaysky et al., 2003) or simply never learned an association (Rissa brevirostris: a colour cuing the presence of food; Kitaysky et al., 2006). Although speed of learning is often taken as a measure of cognitive ability, there is increasing evidence that it is a measure that is susceptible to motivation deficits (van Horik \& Madden, 2016) or other non-cognitive factors, such as motor skills (Chaby et al., 2015b; Tebbich et al., 2016). How development affects these factors is not yet clear but it is possible that they may explain much, if not all, the variation in learning speed among individuals. There are also, perhaps counterintuitively, data that suggest that early-life stress may enable an animal to respond more appropriately to stress in adulthood, including when performing cognitive tasks (e.g. Chaby et al., 2015a; Harris et al., 2009).

The impact of early-life experience on cognition provides more than just fundamental knowledge, as shown by the work of Braithwaite and colleagues who have been investigating variation in early-life experience in a range of key fisheries species and its impact on survival of fish post-release (Salvanes et al., 2013). For example, the longer that juvenile rainbow trout Oncorhynchus mykiss are reared with enrichment (including shelter and novel, coloured objects), the better their spatial learning ability, although fish exposed to enrichment later in the juvenile period were better spatial learners than were those exposed that were exposed earlier in the juvenile period (Bergendahl et al., 2016; also for zebrafish Danio rerio: DePasquale et al., 2016). Although there is little direct evidence that such variation in cognitive abilities improves the post-release survival of these animals, it does seem at least plausible (Marzluff \& Swift, 2017).

It looks as if the kind of intervention, the timing of intervention, and probably its duration, are all likely to shape cognitive futures. Given this variation, it seems that experimental investigation of cognitive development across species and traits will be more 
challenging than it has been thus far in the classic developmental model systems of imprinting and song learning (at least in close-ended learners). It has been exceptionally useful that both imprinting and song learning have a characteristic time window during which information is acquired (sensitive period), as that has allowed us to get a good handle on the kind and amount of information that is provided in that window, and thus a specification and quantification of both the information and its impact.

Even though it has been some time since the first experimental work on imprinting and song learning (e.g. Bateson, 1966; Jackson \& Bateson, 1974), there is still much to be learned about these developmental systems. For example, whilst we know a lot about filial imprinting, we are still determining the mechanistic basis of how young birds extract the features of conspecifics (such as their visual or acoustic characteristics), and the kinds of information they extract (evidence for relational learning: Martinho \& Kacelnik, 2016), which may be fundamentally different from the information extracted by human infants (Santolin et al., 2016). Furthermore, the sexes may differ in the patterns (familiar or not) of stimuli that they learn during imprinting, and multimodal stimulation appears to be more effective than stimuli that are just visual or acoustic, at least for Gallus gallus chicks (Versace et al., 2017). Differences in what the sexes learn in early-life may be more general than these results show, as young female zebra finches were faster to learn an auditory discrimination than were young males (Kriengwatana et al., 2016).

\section{The function of cognitive abilities}

This century has seen a real increase in questions being addressed about the function of cognition i.e. the adaptive significance of cognition. These questions are of two general types: 1) questions that begin with knowledge of the biology of the animal, in particular its ecology or typical social context, and that test whether an animal can solve ecologically- 
relevant problems or tasks, and 2) questions that are addressed at determining what fitness advantage there is to better cognitive performance.

The bulk of the work addressing questions of the first kind can be broadly described as being couched in the adaptive specialization framework (e.g. Shettleworth \& Hampton, 1998). Stemming from early data on long-delay taste aversion learning (Rozin \& Kalat, 1971), in the 1990s the relationship between food storing, spatial memory and hippocampal volume became a common model system for exploring the possibility that cognitive traits (spatial memory) might be associated with relevant ecological demands (the retrieval of multiple food items hidden by the storer) faced by the species in question (tits, chickadees, corvids; e.g. Healy, 1995; Healy \& Krebs, 1992). This proved a successful approach, with demonstrations that food-storing birds had better spatial memory and used different information to relocate food than did nonstorers (Biegler et al., 2001; Brodbeck \& Shettleworth, 1992), at least in some contexts (Hodgson \& Healy, 2005). It is continuing to be a fruitful way to explore the cognitive capacities of food storers that vary in the degree to which they rely on their stored food (e.g. Freas et al., 2013; Roth et al., 2012), as well as the neural basis of their memories (Sherry \& MacDougall-Shackleton, 2015).

The adaptive specialization approach has also been used as the basis for investigating cognitive abilities of foraging hummingbirds. It would seem advantageous for territorial hummingbirds to remember flowers they have recently emptied so as to avoid them until there is a good chance they will have refilled (at least a couple of hours). To do this, the birds would have to remember both a flower's location and when it was emptied, and, indeed hummingbirds can do this (Gonzalez-Gomez et al., 2011; Jelbert et al., 2014; Marshall et al., 2013). Perhaps one of the most surprising findings from this work was that, although it is commonly assumed that hummingbirds prefer red flowers over those of other colours, colour is a cue they only use when there is no useful spatial cue (Marshall et al., 
2012; Samuels et al., 2014; Tello Ramos et al., 2014). Hummingbirds also appear to use space differently from at least rodents (Flores-Abreu et al., 2014). Together with data from other groups of animals that move through 3-D space (fish and bats), the difference suggests that an animal's type of locomotion might affect the way in which they remember spatial locations (Heys et al., 2013; Holbrook \& de Perera, 2011, 2013) but this suggestion needs to be addressed explicitly.

It is not just foraging that provides a context in which cognitive abilities might be useful. Famous for their elaborately decorated bowers and the role those bower decorations play in sexual selection, bowerbirds are also attracting interest with regard to their cognitive abilities. Indeed, some very elegant experimental manipulations by Kelley and Endler (2012b) have shown that males use much more than the number of decorations to attract females: in the great bowerbird Ptilonorhynchus nuchalis, bower-owning males manipulate their females into mating by presenting them with decorations arrayed in a visual illusion known as forced perspective. If the placement of the objects is disrupted and the illusion destroyed, males return the objects to the appropriate place and by so doing, gain more matings (Kelley \& Endler, 2012a).

Perceptual effects have largely been the focus of other work on the role of cognition in mate choice, with psychophysical laws explaining, for example, perception of calls by female tungara frogs Physalaemus pustulosus and also the degree to which females lead males to elaborate their calls (Akre \& Ryan, 2011). Similarly, in the Emei music frog, Babina daunchina, it is the ability of the female to discriminate a male's notes that impacts on the evolution of signals (Cui et al., 2016).

Whether or not females prefer males with better cognitive abilities is, however, very much open for debate (Rowe \& Healy, 2014), let alone whether they gain any fitness advantage from choosing smart partners. Lots of evidence in favour comes from songbirds, 
as females prefer some attributes of male song over others, especially with regard to the complexity of song the male sings, and as song learning is a cognitive trait, then females do clearly prefer males with better cognitive abilities (review in Riebel, 2009). But it is not at all clear whether song is correlated with other cognitive traits: there currently seems to be more evidence for an absence of a correlation (Boogert et al., 2011; Chantal et al., 2016; Templeton et al., 2014) or for a negative correlation (Boogert et al., 2011; Sewall et al., 2013) than there is in favour of a positive correlation (Boogert et al., 2011). In the most thorough examination to date (Anderson et al., 2017), with five cognitive tasks (novel foraging task, colour association, colour reversal, detour-reaching, and spatial learning) and three measures of song learning (complexity, proportion and accuracy of copying), there was a very mixed pattern of relationships between song measures and task performance. Better singers did do better at colour reversal and spatial learning but more poorly on the novel foraging and detour-reaching tasks, results that do not concur with previous outcomes on similar tasks (Boogert et al., 2011; Sewall et al., 2013).

Is it that song learning is not a cognitive ability? Or is it that cognitive abilities do not necessarily correlate with each other (Rowe \& Healy, 2014)? These kinds of questions are being asked as effort is put into determining the role that cognition plays in fitness in animals in the wild (Morand-Ferron \& Quinn, 2015). At the outset of this work, there was an assumption that cognitive traits would be correlated and, therefore, investigating any single trait would be sufficient (Cole et al., 2011; Cole et al., 2012). Because this work was being directed at animals in the wild, it meant that the typical laboratory methods of testing animals were rarely available (outside an acoustic context, e.g. Carlson et al., 2017; Coye et al., 2016) until the implementation of 'problem-solving', which typically entailed requiring an animal to get into a container to reach food. How the animal got into the container may have required quite a lot of dexterity (e.g. Picard et al., 2017; van de Waal et al., 2015), 
some manipulative skills (e.g. Diquelou et al., 2016) or little or no finesse (e.g. BensonAmram \& Holekamp, 2012), and sometimes may have been about removing a container altogether (e.g. Keagy et al., 2009). Whatever the manner in which it managed to access the food, the successful animal was considered to have used some kind of cognitive ability in reaching its target. With increasing use, however, quite what this method of investigating cognitive abilities reveals is starting to receive more attention, with data and conflicting results suggesting a range of possible alternative explanations for variation in task performance, including motivation, motor skills, and neophobia (Griffin et al., 2014; Holekamp et al., 2015; Tebbich et al., 2016; van Horik et al., 2017; van Horik \& Madden, 2016). The corollary of this reassessment of problem-solving is that any fitness benefits that might have been attributed to performance on this kind of task also have to be given more thought.

\section{The mechanistic basis of cognition}

While there has been a flurry of attention directed especially at the functional aspects of cognition, work on its mechanistic basis (to which most effort in cognition is addressed) has calmly proceeded, again with an increasing diversity of species, contexts and experimental paradigms. Some of the work keeps much to traditional lines, such as mechanisms underlying decision-making in rats (Zentall et al., 2017), processing of words and nonwords in pigeons (Scarf et al., 2016), and serial reversal learning in monkeys (Hassett \& Hampton, 2017).

But as above, the variety of species for which the cognitive capacities are now being investigated continues to blossom. For example, in our 'natural history of memory', we now know that red-footed tortoises Chelonoidis carbonaria can remember visual associations for at least 18 months (Soldati et al., 2017), whereas Electric yellow cichlids 
Labidochromis caeruleus can remember an association for at least 12 days, a difference in memory capability that seems likely to be due to testing conditions rather than to a real poverty of recollection in the cichlids (also seen in tests of memory in jumping spiders, Peckmezian \& Taylor, 2017). We can also add a new diversity of species to descriptions of the cues animals use to return to rewarding locations. For instance, the terrestrial toad, Rhinella arenarum, uses visual cues to orient itself much as do other vertebrates (Daneri et al., 2015), whilst the use of visual cues in freshwater stingrays Potamotrygon motoro is context-dependent, as also seen in other vertebrates (Schluessel et al., 2015). And yet, we still do not know how birds (or other vertebrates) put such information together in order to return to a rewarded location in the wild. It has been assumed that they use information about the distance and/or direction of the goal from one or more landmarks to compute the location of the goal (Gould et al., 2010), but wild foraging hummingbirds, at least, do not seem to do this. Rather, their behaviour seems to be more similar to that of the Hymenoptera, using views or panoramas (Pritchard et al., 2015; Sturzl et al., 2016), although the hummingbirds do not undertake elaborate learning flights or turn back to look at rewarding locations (Robert et al., 2017).

An increasing number of animals have been found to have some kind of number skill, whether numerosity, counting, sequencing or something similar (Bar-Shai et al., 2011; Garland \& Low, 2014; Petrazzini et al., 2017; Petrazzini et al., 2015; Tello Ramos et al., 2015), and while most investigation into timing ability is still undertaken in pigeons and rats (e.g. Smith et al., 2017), possums Trichosurus vulpecula and long-tailed bats Glossophaga soricina are now included in the list of species that are able to time intervals (Sargisson et al., 2016; Toelch \& Winter, 2013).

Alongside the increasing interest and access to the cognitive abilities of animals in the wild, we are increasingly discovering how real-world contexts impact on those abilities. 
For example, natural levels of plant secondary metabolites, including nicotine, impair memory for flower colour in foraging Palestine sunbirds, Nectarinia osea, which forage naturally on tree tobacco Nicotiana glauca (Kaczorowski \& Markman, 2016).

Unfortunately, it is human-imposed levels of neonicotinoids that impair spatial memory in bumblebees (Samuelson et al., 2016), odour coding in honeybees (Andrione et al., 2016), and sex allocation decision-making in parasitic wasps (Cook et al., 2016; Whitehorn et al., 2015).

\section{Conclusions}

This has been a whistle-stop overview of animal cognition as it looks in the middle of 2017. It has been extraordinarily easy to confine the majority of references to the years between 2015 and 2017 because the field of animal cognition is more than alive and well, it is thrusting its way into behaviour, evolution, psychology and neuroscience, as well as into multiple public fora. There is an appetite to find out whether animals are intelligent, whether their intelligence resembles ours in any form, and how their cognitive abilities have evolved. And I haven't even touched on the wealth of new data coming from investigations into social learning, the spread of information through social networks that shapes conformity and culture (Aplin et al., 2015; Farine et al., 2015; Whiten et al., 2016b; Whiten \& van de Waal, 2016), concept learning (Wright et al., 2017) or physical cognition, from string pulling (Alem et al., 2016; Audet et al., 2016), tool use (Auersperg et al., 2016; Boesch et al., 2017; Tan, 2017) and nest building (Bailey et al., 2014; Guillette et al., 2016). A fair proportion of this work is still in its early stages, as experimental designs continue to be finessed, and there remains a good deal to be done to establish a thorough theoretical framework for animal cognition. There also needs to be care taken not to assume cognitive abilities from behavioural data simply because researchers consider a behaviour 
to be 'cognitive', researchers need to remember that behavioural changes provide only a conduit to cognitive abilities. For example, problem solving need not be a cognitive task and researchers using this methodology need to be careful with their interpretation of an animal's performance (Tebbich et al., 2016). Likewise, the particular cognitive abilities required to use a tool are still to be comprehensively described. However, aidedby increasingly sophisticated technology, animal cognition is now well and truly out of the box, out of the laboratory, and into the wild (Pritchard et al., 2016), where we really can ask all of Tinbergen's questions.

\section{References}

Akre, K. L., \& Ryan, M. J. (2011). Female tungara frogs elicit more complex mating signals from males. Behavioral Ecology, 22, 846-853. doi: 10.1093/beheco/arr065

Alem, S., Perry, C. J., Zhu, X., Loukola, O. J., Ingraham, T., Sovik, E., \& Chittka, L. (2016). Associative mechanisms allow for social learning and cultural transmission of string pulling in an insect. Plos Biology, 14. doi: 10.1371/journal.pbio.1002564

Anderson, R. C., Searcy, W. A., Peters, S., Hughes, M., DuBois, A. L., \& Nowicki, S. (2017). Song learning and cognitive ability are not consistently related in a songbird. Animal Cognition, 20, 309-320. doi: 10.1007/s10071-016-1053-7

Andrione, M., Vallortigara, G., Antolini, R., \& Haase, A. (2016). Neonicotinoid-induced impairment of odour coding in the honeybee. Scientific Reports, 6, 38110 doi: $10.1038 / \operatorname{srep} 38110$ 
Aplin, L. M., Farine, D. R., Morand-Ferron, J., Cockburn, A., Thornton, A., \& Sheldon, B. C. (2015). Experimentally induced innovations lead to persistent culture via conformity in wild birds. Nature, 518, 538-541. doi: 10.1038/nature13998

Arbib, M. A. (2017). Toward the language-ready brain: biological evolution and primate comparisons. Psychonomic Bulletin \& Review, 24, 142-150. doi: 10.3758/s13423016-1098-2

Audet, J. N., Ducatez, S., \& Lefebvre, L. (2016). Bajan birds pull strings: Two wild Antillean species enter the select club of string-pullers. Plos One, 11. doi: 10.1371/journal.pone.0156112

Auersperg, A. M. I., Borasinski, S., Laumer, I., \& Kacelnik, A. (2016). Goffin's cockatoos make the same tool type from different materials. Biology Letters, 12. doi: 10.1098/rsbl.2016.0689

Auersperg, A. M. I., Szabo, B., von Bayern, A. M. P., \& Bugnyar, T. (2014). Object permanence in the Goffin Cockatoo (Cacatua goffini). Journal of Comparative Psychology, 128, 88-98. doi: 10.1037/a0033272

Bailey, I. E., Morgan, K. V., Bertin, M., Meddle, S. L., \& Healy, S. D. (2014). Physical cognition: birds learn the structural efficacy of nest material. Proceedings of the Royal Society B, 281, 20133225. doi: 10.1098/rspb.2013.3225

Balda, R. P., \& Kamil, A. C. (1998). The ecology and evolution of spatial memory in corvids of the Southwestern USA: The perplexing Pinyon Jay. In R. P. Balda, I. M. Pepperberg \& A. C. Kamil (Eds.), Animal Cognition in Nature. The convergence of pyschology and biology in laboratory and field (pp. 29-64). San Diego, California 92101-4495, USA: Academic Press. 
Balda, R. P., Pepperberg, I. M., \& Kamil, A. C. (Eds.). (1998). Animal Cognition in Nature. The convergence of pyschology and biology in laboratory and field. San Diego, California 92101-4495, USA: Academic Press.

Baptista, L. F., Nelson, D. A., \& Gaunt, S. L. L. (1998). Cognitive processes in avian vocal acquisition. In R. P. Balda, I. M. Pepperberg \& A. C. Kamil (Eds.), Animal Cognition in Nature. The convergence of pyschology and biology in laboratory and field (pp. 245-274). San Diego, California 92101-4495, USA: Academic Press.

Bar-Shai, N., Keasar, T., \& Shmida, A. (2011). The use of numerical information by bees in foraging tasks. Behavioral Ecology, 22, 317-325. doi: 10.1093/beheco/arq206

Bateson, P. P. G. (1966). Characteristics and context of imprinting. Biological Reviews of the Cambridge Philosophical Society, 41, 177-217. doi: 10.1111/j.1469185X.1966.tb01489.x

Bebus, S. E., Small, T. W., Jones, B. C., Elderbrock, E. K., \& Schoech, S. J. (2016). Associative learning is inversely related to reversal learning and varies with nestling corticosterone exposure. Animal Behaviour, 111, 251-260. doi: 10.1016/j.anbehav.2015.10.027

Beer, C. G. (1998). Varying views of animal and human cognition. In R. P. Balda, I. M. Pepperberg \& A. C. Kamil (Eds.), Animal Cognition in Nature. The convergence of pyschology and biology in laboratory and field (pp. 435-456). San Diego, California 92101-4495, USA: Academic Press.

Benson-Amram, S., \& Holekamp, K. E. (2012). Innovative problem solving by wild spotted hyenas. Proceedings of the Royal Society B, 279, 4087-4095. doi: 10.1098/rspb.2012.1450 
Bergendahl, I. A., Salvanes, A. G. V., \& Braithwaite, V. A. (2016). Determining the effects of duration and recency of exposure to environmental enrichment. Applied Animal Behaviour Science, 176, 163-169. doi: 10.1016/j.applanim.2015.11.002

Biegler, R., McGregor, A., Krebs, J. R., \& Healy, S. D. (2001). A larger hippocampus is associated with longer-lasting spatial memory. Proceedings of the National Academy of Sciences (U.S.A.), 98, 6941-6944. doi: 10.1073/pnas.121034798

Bingman, V. P., Riters, L. V., Strasser, R., \& Gagliardo, A. (1998). Neuroethology of avian navigation. In R. P. Balda, I. M. Pepperberg \& A. C. Kamil (Eds.), Animal Cognition in Nature. The convergence of pyschology and biology in laboratory and field (pp. 201-226). San Diego, California 92101-4495, USA: Academic Press.

Boesch, C., Bombjakova, D., Boyette, A., \& Meier, A. (2017). Technical intelligence and culture: Nut cracking in humans and chimpanzees. American Journal of Physical Anthropology, 163, 339-355. doi: 10.1002/ajpa.23211

Boogert, N. J., Anderson, R. C., Peters, S., Searcy, W. A., \& Nowicki, S. (2011). Song repertoire size in male song sparrows correlates with detour reaching, but not with other cognitive measures. Animal Behaviour, 81, 1209-1216. doi:

10.1016/j.anbehav.2011.03.004

Bourjade, M., Meguerditchian, A., Maille, A., Gaunet, F., \& Vauclair, J. (2014). Olive baboons, Papio anubis, adjust their visual and auditory intentional gestures to the visual attention of others. Animal Behaviour, 87, 121-128. doi:

10.1016/j.anbehav.2013.10.019

Brodbeck, D. R., \& Shettleworth, S. J. (1992). Do food-storing birds remember different things from nonstorers. Bulletin of the Psychonomic Society, 30, 485-486. 
Bugnyar, T., \& Heinrich, B. (2005). Ravens, Corvus corax, differentiate between knowledgeable and ignorant competitors. Proceedings of the Royal Society B, 272, 1641-1646. doi: 10.1098/rspb.2005.3144

Bugnyar, T., Reber, S. A., \& Buckner, C. (2016). Ravens attribute visual access to unseen competitors. Nature Communications, 7. doi: 10.1038/ncomms10506

Carlson, N. V., Healy, S. D., \& Templeton, C. N. (2017). A comparative study of how British tits encode predator threat in their mobbing calls. Animal Behaviour, 125, 77-92. doi: 10.1016/j.anbehav.2017.01.011

Chaby, L. E., Cavigelli, S. A., Hirrlinger, A. M., Lim, J., Warg, K. M., \& Braithwaite, V. A. (2015a). Chronic stress during adolescence impairs and improves learning and memory in adulthood. Frontiers in Behavioral Neuroscience, 9. doi:

10.3389/fnbeh.2015.00327

Chaby, L. E., Sheriff, M. J., Hirrlinger, A. M., Lim, J., Fetherston, T. B., \& Braithwaite, V. A. (2015b). Does chronic unpredictable stress during adolescence affect spatial cognition in adulthood? Plos One, 10. doi: 10.1371/journal.pone.0141908

Chantal, V., Gibelli, J., \& Dubois, F. (2016). Male foraging efficiency, but not male problem-solving performance, influences female mating preferences in zebra finches. Peerj, 4. doi: 10.7717/peerj.2409

Clary, D., \& Kelly, D. M. (2016). Graded mirror self-recognition by Clark's nutcrackers. Scientific Reports, 6. doi: 10.1038/srep36459

Clayton, N. S., Dally, J. M., \& Emery, N. J. (2007). Social cognition by food-caching corvids. The western scrub-jay as a natural psychologist. Philosophical Transactions of the Royal Society B, 362, 507-522. doi: 10.1098/rstb.2006.1992

Clayton, N. S., \& Emery, N. J. (2015). Avian models for human cognitive neuroscience: A proposal. Neuron, 86, 1330-1342. doi: 10.1016/j.neuron.2015.04.024 
Clayton, N. S., \& Lee, D. W. (1998). Memory and hippocampus in food-storing birds. In R. P. Balda, I. M. Pepperberg \& A. C. Kamil (Eds.), Animal Cognition in Nature. The convergence of pyschology and biology in laboratory and field (pp. 99-118). San Diego, California 92101-4495, USA: Academic Press.

Cole, E. F., Cram, D. L., \& Quinn, J. L. (2011). Individual variation in spontaneous problem-solving performance among wild great tits. Animal Behaviour, 81, 491498. doi: 10.1016/j.anbehav.2010.11.025

Cole, E. F., Morand-Ferron, J., Hinks, A. E., \& Quinn, J. L. (2012). Cognitive ability influences reproductive life history variation in the wild. Current Biology, 22, 18081812. doi: 10.1016/j.cub.2012.07.051

Cook, N., Green, J., Shuker, D. M., \& Whitehorn, P. R. (2016). Exposure to the neonicotinoid imidacloprid disrupts sex allocation cue use during superparasitism in the parasitoid wasp Nasonia vitripennis. Ecological Entomology, 41, 693-697. doi: 10.1111/een.12344

Costa, J. H. C., von Keyserlingk, M. A. G., \& Weary, D. M. (2016). Invited review: Effects of group housing of dairy calves on behavior, cognition, performance, and health. Journal of Dairy Science, 99, 2453-2467. doi: 10.3168/jds.2015-10144

Coye, C., Zuberbuhler, K., \& Lemasson, A. (2016). Morphologically structured vocalizations in female Diana monkeys. Animal Behaviour, 115, 97-105. doi: 10.1016/j.anbehav.2016.03.010

Cui, J. G., Song, X. W., Zhu, B. C., Fang, G. Z., Tang, Y. Z., \& Ryan, M. J. (2016). Receiver discriminability drives the evolution of complex sexual signals by sexual selection. Evolution, 70, 922-927. doi: 10.1111/evo.12889

Cussen, V. A. (2017). Psittacine cognition: Individual differences and sources of variation. Behavioural Processes, 134, 103-109. doi: 10.1016/j.beproc.2016.11.008 
Daneri, M. F., Casanave, E. B., \& Muzio, R. N. (2015). Use of local visual cues for spatial orientation in terrestrial toads (Rhinella arenarum): The role of distance to a goal. Journal of Comparative Psychology, 129, 247-255. doi: 10.1037/a0039461

DePasquale, C., Neuberger, T., Hirrlinger, A. M., \& Braithwaite, V. A. (2016). The influence of complex and threatening environments in early life on brain size and behaviour. Proceedings of the Royal Society B, 283. doi: 10.1098/rspb.2015.2564

Devoogd, T. J., \& Székely, T. (1998). Causes of avian song: Using neurobiology to integrate proximate and ultimate levels of analysis. In R. P. Balda, I. M. Pepperberg \& A. C. Kamil (Eds.), Animal Cognition in Nature. The convergence of pyschology and biology in laboratory and field (pp. 337-380.). San Diego, California 921014495, USA: Academic Press.

Diquelou, M. C., Griffin, A. S., \& Sol, D. (2016). The role of motor diversity in foraging innovations: a cross-species comparison in urban birds. Behavioral Ecology, 27, 584-591. doi: 10.1093/beheco/arv190

Dyer, F. C. (1998). Spatial cognition: Lessons from central-place foraging insects. In R. P. Balda, I. M. Pepperberg \& A. C. Kamil (Eds.), Animal Cognition in Nature. The convergence of pyschology and biology in laboratory and field (pp. 119-154). San Diego, California 92101-4495, USA: Academic Press.

Farine, D. R., Aplin, L. M., Sheldon, B. C., \& Hoppitt, W. (2015). Interspecific social networks promote information transmission in wild songbirds. Proceedings of the Royal Society B, 282. doi: 10.1098/rspb.2014.2804

Farrell, T. M., Morgan, A., \& MacDougall-Shackleton, S. A. (2016). Developmental stress impairs performance on an association task in male and female songbirds, but impairs auditory learning in females only. Animal Cognition, 19, 1-14. doi: 10.1007/s10071-015-0908-7 
Flores-Abreu, I. N., Hurly, T. A., Ainge, J. A., \& Healy, S. D. (2014). Three-dimensional space: locomotory style explains memory differences in rats and hummingbirds. Proceedings of the Royal Society B, 281. doi: 10.1098/rspb.2014.0301

Freas, C. A., Bingman, K., LaDage, L. D., \& Pravosudov, V. V. (2013). Untangling elevation-related differences in the hippocampus in food-caching mountain chickadees: The effect of a uniform captive environment. Brain Behavior and Evolution, 82, 199-209. doi: 10.1159/000355503

Gajdon, G. K., Ortner, T. M., Wolf, C. C., \& Huber, L. (2013). How to solve a mechanical problem: the relevance of visible and unobservable functionality for kea. Animal Cognition, 16, 483-492. doi: 10.1007/s10071-012-0588-5

Garland, A., \& Low, J. (2014). Addition and subtraction in wild New Zealand robins. Behavioural Processes, 109, 103-110. doi: 10.1016/j.beproc.2014.08.022

Gonzalez-Gomez, P. L., Bozinovic, F., \& Vasquez, R. A. (2011). Elements of episodic-like memory in free-living hummingbirds, energetic consequences. Animal Behaviour, 81, 1257-1262. doi: 10.1016/j.anbehav.2011.03.014

Goodall, J. (1986). The Chimpanzees of Gombe: Patterns of Behavior Boston: Bellknap Press of the Harvard University Press.

Gould, K. L., Kelly, D. M., \& Kamil, A. C. (2010). What scatter-hoarding animals have taught us about small-scale navigation. Philosophical Transactions of the Royal Society B, 365, 901-914. doi: 10.1098/rstb.2009.0214

Graham, K. E., Furuichi, T., \& Byrne, R. W. (2017). The gestural repertoire of the wild bonobo (Pan paniscus): a mutually understood communication system. Animal Cognition, 20, 171-177. doi: 10.1007/s10071-016-1035-9 
Griffin, A. S., Diquelou, M., \& Perea, M. (2014). Innovative problem solving in birds: a key role of motor diversity. Animal Behaviour, 92, 221-227. doi:

10.1016/j.anbehav.2014.04.009

Guillette, L. M., Scott, A. C. Y., \& Healy, S. D. (2016). Social learning in nest-building birds: a role for familiarity. Proceedings of the Royal Society B, 283. doi:

$10.1098 / \mathrm{rspb} .2015 .2685$

Gunhold, T., Whiten, A., \& Bugnyar, T. (2014). Video demonstrations seed alternative problem-solving techniques in wild common marmosets. Biology Letters, 10. doi: $10.1098 /$ rsbl.2014.0439

Harris, A. P., D'Eath, R. B., \& Healy, S. D. (2009). Environmental enrichment enhances spatial cognition in rats by reducing thigmotaxis (wall hugging) during testing. Animal Behaviour, 77, 1459-1464. doi: 10.1016/j.anbehav.2009.02.019

Hassett, T. C., \& Hampton, R. R. (2017). Change in the relative contributions of habit and working memory facilitates serial reversal learning expertise in rhesus monkeys. Animal Cognition, 20, 485-497. doi: 10.1007/s10071-017-1076-8

Healy, S. D. (1995). Memory for objects and positions: delayed non-matching-to-sample in storing and nonstoring tits. Quarterly Journal of Experimental Psychology B, 48, 179-191.

Healy, S. D., \& Krebs, J. R. (1992). Delayed-matching-to-sample by marsh tits and great tits. Quarterly Journal of Experimental Psychology B, 45B, 33-47.

Heys, J. G., MacLeod, K. M., Moss, C. F., \& Hasselmo, M. E. (2013). Bat and rat neurons differ in theta-frequency resonance despite similar coding of space. Science, 340, 363-367. doi: 10.1126/science. 1233831

Hobaiter, C., \& Byrne, R. W. (2014). The meanings of chimpanzee gestures. Current Biology, 24, 1596-1600. doi: 10.1016/j.cub.2014.05.066 
Hodgson, Z. G., \& Healy, S. D. (2005). Preference for spatial cues in a non-storing songbird species. Animal Cognition, 8, 211-214. doi: 10.1007/s10071-004-0249-4

Holbrook, R. I., \& de Perera, T. B. (2011). Three-dimensional spatial cognition: information in the vertical dimension overrides information from the horizontal. Animal Cognition, 14, 613-619. doi: 10.1007/s10071-011-0393-6

Holbrook, R. I., \& de Perera, T. B. (2013). Three-dimensional spatial cognition: freely swimming fish accurately learn and remember metric information in a volume. Animal Behaviour, 86, 1077-1083. doi: 10.1016/j.anbehav.2013.09.014

Holekamp, K. E., \& Benson-Amram, S. (2017). The evolution of intelligence in mammalian carnivores. Interface Focus, 7. doi: 10.1098/rsfs.2016.0108

Holekamp, K. E., Dantzer, B., Stricker, G., Yoshida, K. C. S., \& Benson-Amram, S. (2015). Brains, brawn and sociality: a hyaena's tale. Animal Behaviour, 103, 237248. doi: 10.1016/j.anbehav.2015.01.023

Holveck, M. J., \& Riebel, K. (2010). Low-quality females prefer low-quality males when choosing a mate. Proceedings of the Royal Society B, 277, 153-160. doi: $10.1098 /$ rspb.2009.1222

Hunt, G. R. (1996). Manufacture and use of hook-tools by New Caledonian crows. Nature, 379, 249-251. doi: 10.1038/379249a0

Jackson, P. S., \& Bateson, P. P. G. (1974). Imprinting and exploration of slight novelty in chicks. Nature, 251, 609-610. doi: 10.1038/251609a0

Jelbert, S. A., Hurly, T. A., Marshall, R. E. S., \& Healy, S. D. (2014). Wild, free-living hummingbirds can learn what happened, where and in which context. Animal Behaviour, 89, 185-189. doi: 10.1016/j.anbehav.2013.12.028 
Kaczorowski, R. L., \& Markman, S. (2016). Nectar alkaloids of tree tobacco can reduce Palestine sunbird foraging performance in a colour discrimination task. Animal Behaviour, 119, 59-68. doi: 10.1016/j.anbehav.2016.05.015

Keagy, J., Savard, J. F., \& Borgia, G. (2009). Male satin bowerbird problem-solving ability predicts mating success. Animal Behaviour, 78, 809-817. doi:

10.1016/j.anbehav.2009.07.011

Kelley, L. A., \& Endler, J. A. (2012a). Illusions promote mating success in great bowerbirds. Science, 335, 335-338. doi: 10.1126/science.1212443

Kelley, L. A., \& Endler, J. A. (2012b). Male great bowerbirds create forced perspective illusions with consistently different individual quality. Proceedings of the National Academy of Sciences (U.S.A.), 109, 20980-20985. doi: 10.1073/pnas.1208350109

Kis, A., Huber, L., \& Wilkinson, A. (2015). Social learning by imitation in a reptile (Pogona vitticeps). Animal Cognition, 18, 325-331. doi: 10.1007/s10071-014-08037

Kitaysky, A. S., Kitaiskaia, E., Piatt, J., \& Wingfield, J. C. (2003). Benefits and costs of increased levels of corticosterone in seabird chicks. Hormones and Behavior, 43, 140-149. doi: 10.1016/s0018-506x(02)00030-2

Kitaysky, A. S., Kitaiskaia, E. V., Piatt, J. F., \& Wingfield, J. C. (2006). A mechanistic link between chick diet and decline in seabirds? Proceedings of the Royal Society B, 273, 445-450. doi: 10.1098/rspb.2005.3351

Köhler, W. (1925). The Mentality of Apes (E. Winter, Trans.). London: Kegan, Trench Kriengwatana, B., Spierings, M. J., \& ten Cate, C. (2016). Auditory discrimination learning in zebra finches: effects of sex, early life conditions and stimulus characteristics. Animal Behaviour, 116, 99-112. doi: 10.1016/j.anbehav.2016.03.028 
Lakatos, G., Gacsi, M., Topal, J., \& Miklosi, A. (2012). Comprehension and utilisation of pointing gestures and gazing in dog-human communication in relatively complex situations. Animal Cognition, 15, 201-213. doi: 10.1007/s10071-011-0446-X

Marshall, R. E. S., Hurly, T. A., \& Healy, S. D. (2012). Do a flower's features help hummingbirds to learn its contents and refill rate? Animal Behaviour, 83, 11631169. doi: 10.1016/j.anbehav.2012.02.003

Marshall, R. E. S., Hurly, T. A., Sturgeon, J., Shuker, D. M., \& Healy, S. D. (2013). What, where and when: deconstructing memory. Proceedings of the Royal Society B, 280. doi: $10.1098 /$ rspb.2013.2194

Martinho, A., III, \& Kacelnik, A. (2016). Ducklings imprint on the relational concept of "same or different". Science, 353, 286-288. doi: 10.1126/science.aaf4247

Marzluff, J. M., \& Swift, K. N. (2017). Connecting animal and human cognition to conservation. Current Opinion in Behavioral Sciences, 16, 87-92. doi: 10.1016/j.cobeha.2017.04.005

Miklosi, A., \& Kubinyi, E. (2016). Current trends in canine problem-solving and cognition. Current Directions in Psychological Science, 25, 300-306. doi: $10.1177 / 0963721416666061$

Morand-Ferron, J., \& Quinn, J. L. (2015). The evolution of cognition in natural populations. Trends in Cognitive Sciences, 19, 235-237. doi: 10.1016/j.tics.2015.03.005

Nawroth, C., Baciadonna, L., \& McElligott, A. G. (2016). Goats learn socially from humans in a spatial problem-solving task. Animal Behaviour, 121, 123-129. doi: 10.1016/j.anbehav.2016.09.004

Peckmezian, T., \& Taylor, P. W. (2017). Place avoidance learning and memory in a jumping spider. Animal Cognition, 20, 275-284. doi: 10.1007/s10071-016-1048-4 
Pepperberg, I. M. (2017). Avian numerical cognition: A review and brief comparisons to non-avian species. In C. ten Cate \& S. D. Healy (Eds.), Avian Cognition (pp. 184207). Cambridge: Cambridge University Press.

Petrazzini, M. E. M., Agrillo, C., Izard, V., \& Bisazza, A. (2016). Do humans (Homo sapiens) and fish (Pterophyllum scalare) make similar numerosity judgments? Journal of Comparative Psychology, 130, 380-390. doi: 10.1037/com0000045

Petrazzini, M. E. M., Fraccaroli, I., Gariboldi, F., Agrillo, C., Bisazza, A., Bertolucci, C., \& Foa, A. (2017). Quantitative abilities in a reptile (Podarcis sicula). Biology Letters, 13. doi: 10.1098/rsbl.2016.0899

Petrazzini, M. E. M., Lucon-Xiccato, T., Agrillo, C., \& Bisazza, A. (2015). Use of ordinal information by fish. Scientific Reports, 5. doi: 10.1038/srep15497

Picard, A. M., Hogan, L., Lambert, M. L., Wilkinson, A., Seed, A. M., \& Slocombe, K. E. (2017). Diffusion of novel foraging behaviour in Amazon parrots through social learning. Animal Cognition, 20, 285-298. doi: 10.1007/s10071-016-1049-3

Pravosudov, V. V., Lavenex, P., \& Omanska, A. (2005). Nutritional deficits during early development affect hippocampal structure and spatial memory later in life. Behavioral Neuroscience, 119, 1368-1374. doi: 10.1037/0735-7044.119.5.1368

Pritchard, D. J., Hurly, T. A., \& Healy, S. D. (2015). Effects of landmark distance and stability on accuracy of reward relocation. Animal Cognition, 18, 1285-1297. doi: $10.1007 / \mathrm{s} 10071-015-0896-7$

Pritchard, D. J., Hurly, T. A., Tello-Ramos, M. C., \& Healy, S. D. (2016). Why study cognition in the wild (and how to test it)? Journal of the Experimental Analysis of Behavior, 105, 41-55. doi: 10.1002/jeab.195 
Riebel, K. (2009). Song and female mate choice in zebra finches: A review. In M. Naguib, K. Zuberbuhler, N. S. Clayton \& V. M. Janik (Eds.), Advances in the Study of Behavior (Vol. 40, pp. 197-238).

Robert, T., Frasnelli, E., Collett, T. S., \& de Ibarra, N. H. (2017). Male bumblebees perform learning flights on leaving a flower but not when leaving their nest. Journal of Experimental Biology, 220, 930-937. doi: 10.1242/jeb.151126

Roth, T. C., Ladage, L. D., Freas, C. A., \& Pravosudov, V. V. (2012). Variation in memory and the hippocampus across populations from different climates: a common garden approach. Integrative and Comparative Biology, 52, E150-E150.

Rowe, C., \& Healy, S. D. (2014). Measuring variation in cognition. Behavioral Ecology, 25, 1287-1292. doi: 10.1093/beheco/aru090

Rozin, P., \& Kalat, J. W. (1971). Specific hungers and poison avoidance as adaptive specializations of learning. Psychological Review, 78, 459-\&. doi: $10.1037 / \mathrm{h} 0031878$

Salvanes, A. G. V., Moberg, O., Ebbesson, L. O. E., Nilsen, T. O., Jensen, K. H., \& Braithwaite, V. A. (2013). Environmental enrichment promotes neural plasticity and cognitive ability in fish. Proceedings of the Royal Society B, 280. doi:

10.1098/rspb.2013.1331

Samuels, M., Hurly, T. A., \& Healy, S. D. (2014). Colour cues facilitate learning flower refill schedules in wild hummingbirds. Behavioural Processes, 109, 157-163.

Samuelson, E. E. W., Chen-Wishart, Z. P., Gill, R. J., \& Leadbeater, E. (2016). Effect of acute pesticide exposure on bee spatial working memory using an analogue of the radial-arm maze. Scientific Reports, 6. doi: 10.1038/srep38957 
Santolin, C., Rosa-Salva, O., Regolin, L., \& Vallortigara, G. (2016). Generalization of visual regularities in newly hatched chicks (Gallus gallus). Animal Cognition, 19, 1007-1017. doi: 10.1007/s10071-016-1005-2

Sargisson, R. J., Lockhart, R. A., McEwan, J. S., \& Bizo, L. A. (2016). Demonstration of the scalar property of timing with possums (Trichosurus vulpecula). Journal of Comparative Psychology, 130, 81-86. doi: 10.1037/com0000022

Scarf, D., Boy, K., Reinert, A. U., Devine, J., Gunturkun, O., \& Colombo, M. (2016). Orthographic processing in pigeons (Columba livia). Proceedings of the National Academy of Sciences (U.S.A.), 113, 11272-11276. doi: 10.1073/pnas.1607870113

Schlenker, P., Chemla, E., \& Zuberbuhler, K. (2016). What do monkey calls mean? Trends in Cognitive Sciences, 20, 894-904. doi: 10.1016/j.tics.2016.10.004

Schluessel, V., Herzog, H., \& Scherpenstein, M. (2015). Seeing the forest before the treesspatial orientation in freshwater stingrays (Potamotrygon motoro) in a hole-board task. Behavioural Processes, 119, 105-115. doi: 10.1016/j.beproc.2015.08.001

Schmidt, K. L., MacDougall-Shackleton, E. A., Kubli, S. P., \& MacDougall-Shackleton, S. A. (2014). Developmental stress, condition, and birdsong: A case study in song sparrows. Integrative and Comparative Biology, 54, 568-577. doi: 10.1093/icb/icu090

Schmidt, K. L., McCallum, E. S., MacDougall-Shackleton, E. A., \& MacDougallShackleton, S. A. (2013). Early-life stress affects the behavioural and neural response of female song sparrows to conspecific song. Animal Behaviour, 85, 825837. doi: 10.1016/j.anbehav.2013.01.029

Schuck-Paim, C., Borsari, A., \& Ottoni, E. B. (2009). Means to an end: Neotropical parrots manage to pull strings to meet their goals. Animal Cognition, 12, 287-301. doi: $10.1007 / \mathrm{s} 10071-008-0190-\mathrm{Z}$ 
Sewall, K. B., Soha, J. A., Peters, S., \& Nowicki, S. (2013). Potential trade-off between vocal ornamentation and spatial ability in a songbird. Biology Letters, 9. doi: $10.1098 /$ rsbl.2013.0344

Sherry, D. F., \& MacDougall-Shackleton, S. A. (2015). Seasonal change in the avian hippocampus. Frontiers in Neuroendocrinology, 37, 158-167. doi: 10.1016/j.yfrne.2014.11.008

Shettleworth, S. J. (2001). Animal cognition and animal behaviour. Animal Behaviour, 61, 277-286. doi: 10.1006/anbe.2000.1606

Shettleworth, S. J., \& Hampton, R. R. (1998). Adaptive specialisations of spatial cognition in food-storing birds? Approaches to testing a comparative hypothesis. In R. P. Balda, I. M. Pepperberg \& A. C. Kamil (Eds.), Animal Cognition in Nature. The convergence of pyschology and biology in laboratory and field (pp. 65-98). San Diego, California 92101-4495, USA: Academic Press.

Smith, A. E., Dalecki, S. J., \& Crystal, J. D. (2017). A test of the reward-value hypothesis. Animal Cognition, 20, 215-220. doi: 10.1007/s10071-016-1040-z

Smith, A. V., Proops, L., Grounds, K., Wathan, J., \& McComb, K. (2016). Functionally relevant responses to human facial expressions of emotion in the domestic horse (Equus caballus). Biology Letters, 12. doi: 10.1098/rsbl.2015.0907

Soldati, F., Burman, O. H. P., John, E. A., Pike, T. W., \& Wilkinson, A. (2017). Long-term memory of relative reward values. Biology Letters, 13. doi: 10.1098/rsbl.2016.0853

Spencer, K. A., Buchanan, K. L., Goldsmith, A. R., \& Catchpole, C. K. (2003). Song as an honest signal of developmental stress in the zebra finch (Taeniopygia guttata). Hormones and Behavior, 44, 132-139. doi: 10.1016/s0018-506x(03)00124-7

Spencer, K. A., Wimpenny, J. H., Buchanan, K. L., Lovell, P. G., Goldsmith, A. R., \& Catchpole, C. K. (2005). Developmental stress affects the attractiveness of male 
song and female choice in the zebra finch (Taeniopygia guttata). Behavioral Ecology and Sociobiology, 58, 423-428. doi: 10.1007/s00265-005-0927-5

Sturzl, W., Zeil, J., Boeddeker, N., \& Hemmi, J. M. (2016). How wasps acquire and use views for homing. Current Biology, 26, 470-482. doi: 10.1016/j.cub.2015.12.052

Suzuki, K., Matsunaga, E., Yamada, H., Kobayashi, T., \& Okanoya, K. (2014). Complex song development and stress hormone levels in the Bengalese finch. Avian Biology Research, 7, 10-17. doi: 10.3184/175815514x13903270812502

Tan, A. W. Y. (2017). From play to proficiency: The ontogeny of stone-tool use in coastalforaging long-tailed macaques (Macaca fascicularis) from a comparative perception-action perspective. Journal of Comparative Psychology, 131, 89-114. doi: $10.1037 / \operatorname{com} 0000068$

Tebbich, S., Griffin, A. S., Peschl, M. F., \& Sterelny, K. (2016). From mechanisms to function: an integrated framework of animal innovation. Philosophical Transactions of the Royal Society B, 371. doi: 10.1098/rstb.2015.0195

Teglas, E., Gergely, A., Kupan, K., Miklosi, A., \& Topal, J. (2012). Dogs' gaze following is tuned to human communicative signals. Current Biology, 22, 209-212. doi: 10.1016/j.cub.2011.12.018

Tello Ramos, M. C., Hurly, T. A., \& Healy, S. D. (2014). Female hummingbirds do not relocate rewards using colour cues. Animal Behaviour, 93, 129-133. doi: 10.1016/j.anbehav.2014.04.036

Tello Ramos, M. C., Hurly, T. A., \& Healy, S. D. (2015). Traplining in hummingbirds: flying short-distance sequences among several locations. Behavioral Ecology, 26, 812-819. doi: 10.1093/beheco/arv014 
Templeton, C. N., Laland, K. N., \& Boogert, N. J. (2014). Does song complexity correlate with problem-solving performance in flocks of zebra finches? Animal Behaviour, 92, 63-71. doi: 10.1016/j.anbehav.2014.03.019

Tennie, C., Jensen, K., \& Call, J. (2016). The nature of prosociality in chimpanzees. Nature Communications, 7. doi: 10.1038/ncomms13915

Todt, D., \& Hultsch, H. (1998). Hierarchical learning, development and representation of song. In R. P. Balda, I. M. Pepperberg \& A. C. Kamil (Eds.), Animal Cognition in Nature. The convergence of pyschology and biology in laboratory and field (pp. 275-304). San Diego, California 92101-4495, USA: Academic Press.

Toelch, U., \& Winter, Y. (2013). Interval timing behavior in Pallas's long-tongued bat (Glossophaga soricina). Journal of Comparative Psychology, 127, 445-452. doi: $10.1037 / \mathrm{a} 0032528$

Vale, G. L., Davis, S. J., Lambeth, S. P., Schapiro, S. J., \& Whiten, A. (2017). Acquisition of a socially learned tool use sequence in chimpanzees: Implications for cumulative culture. Evolution and Human Behavior, online 2 May 2017.

van de Waal, E., Claidiere, N., \& Whiten, A. (2015). Wild vervet monkeys copy alternative methods for opening an artificial fruit. Animal Cognition, 18, 617-627. doi: $10.1007 / \mathrm{s} 10071-014-0830-4$

van Horik, J. O., Langley, E. J. G., Whiteside, M. A., \& Madden, J. R. (2017). Differential participation in cognitive tests is driven by personality, sex, body condition and experience. Behavioural Processes, 134, 22-30. doi: 10.1016/j.beproc.2016.07.001 van Horik, J. O., \& Madden, J. R. (2016). A problem with problem solving: motivational traits, but not cognition, predict success on novel operant foraging tasks. Animal Behaviour, 114, 189-198. doi: 10.1016/j.anbehav.2016.02.006 
Versace, E., Spierings, M. J., Caffini, M., ten Cate, C., \& Vallortigara, G. (2017).

Spontaneous generalization of abstract multimodal patterns in young domestic chicks. Animal Cognition, 20, 521-529. doi: 10.1007/s10071-017-1079-5

Wascher, C. A. F., \& Bugnyar, T. (2013). Behavioral responses to inequity in reward distribution and working effort in crows and ravens. Plos One, 8. doi: 10.1371/journal.pone.0056885

Whitehorn, P. R., Cook, N., Blackburn, C. V., Gill, S. M., Green, J., \& Shuker, D. M. (2015). Sex allocation theory reveals a hidden cost of neonicotinoid exposure in a parasitoid wasp. Proceedings of the Royal Society B, 282. doi:

10.1098/rspb.2015.0389

Whiten, A., Allan, G., Devlin, S., Kseib, N., Raw, N., \& McGuigan, N. (2016a). Social learning in the real-world: 'Over-imitation' occurs in both children and adults unaware of participation in an experiment and independently of social interaction. Plos One, 11. doi: 10.1371/journal.pone.0159920

Whiten, A., Caldwell, C. A., \& Mesoudi, A. (2016b). Cultural diffusion in humans and other animals. Current Opinion in Psychology, 8, 15-21. doi:

10.1016/j.copsyc.2015.09.002

Whiten, A., \& van de Waal, E. (2016). Identifying and dissecting conformity in animals in the wild: further analysis of primate data. Animal Behaviour, 122, E1-E4. doi: 10.1016/j.anbehav.2016.04.002

Wright, A. A., Magnotti, J. F., Katz, J. S., Leonardo, K., Vernouillet, A., \& Kelly, D. M. (2017). Corvids outperform pigeons and primates in learning a basic concept. Psychological Science, 28, 437-444. doi: 10.1177/0956797616685871

Zentall, T. R., Case, J. P., \& Berry, J. R. (2017). Rats' acquisition of the ephemeral reward task. Animal Cognition, 20, 419-425. doi: 10.1007/s10071-016-1065-3 